ANUARIO MUSICAL, N. ${ }^{\circ} 65$

enero-diciembre 2010, 3-24

ISSN: 0211-3538

\title{
El tractadista Guillermus de Podio: BASES PER A LA CONSTRUCCIÓ D’UNA BIOGRAFIA
}

\author{
The theorist Guillermus de Podio: \\ FOUNDATIONS FOR THE CONSTRUCTION OF A BIOGRAPHY
}

\author{
Francesc Villanueva Serrano \\ Universitat Politècnica de València
}

Resum:

Sota el nom d'autor de Guillermus de Podio es conserven dues obres de teoria musical de finals del segle xv: l'impresa Ars musicorum (València, Hagenbach i Hutz, 1495) i el manuscrit Enchiridion de principiis musice discipline contra negantes illa et destruentes. Malgrat la gran influència que aquest músic va exercir sobre els teòrics espanyols del segle XVI, són mínimes les seues dades biogràfiques generalment acceptades per la comunitat investigadora. El present article pretén oferir uns fonaments sòlids sobre els quals poder construir la seua biografia. Amb aquesta finalitat, es distingeixen primerament les dades contrastades de les que formen part de l'especulació en la historiografia del músic. Finalment s'aporten nous documents que resolen els dubtes sobre la seua identitat i desvelen el seu magisteri en la seu de València.

\section{Paraules clau:}

Guillermus de Podio; Guillem Molins; Ars musicorum; Teoria musical; Catedral de Barcelona; Joan II d'Aragó; Catedral de València; Cantor; Mestre de cant.

\begin{abstract}
:
Two works of music theory from the endings of the 15th Century with the name of author Guillermus de Podio are preserved: the printed Ars musicorum (València, Hagenbach and Hutz, 1495) and the manuscript Enchiridion de principiis musice discipline contra negantes illa et destruentes. Despite the great influence that this musician exerted on Spanish theorists of the 16th Century, there are only few commonly accepted data about his biography. This article pretends to offer solid foundations to build his biography. In first place, verified from speculated data in the historiography of the musician will be distinguished. Finally, new documents will clarify his identity and will reveal his work as master of chant in the catedral of Valencia.
\end{abstract}

* El contingut d'aquest article forma part d'un estudi biogràfic en profunditat de l'autor que s'integra en la meua tesi doctoral, actualment en redacció. Agraïsc a Antonio Ezquerro Esteban, director de la meua tesi, la seua amabilitat en realitzar una lectura crítica a aquest article prèvia a la seua publicació, així com en ajudar-me en la localització de bibliografia de difícil accés. Així mateix, deixe constància de la inestimable ajuda de Xavier Serra Estellés en la transcripció i la traducció dels documents llatins, a qui dec la resolució acurada i minuciosa dels meus dubtes. Finalment, trasllade els meus agraïments als canonges arxivers de la catedral de València, Salvador Vázquez i Vicent Pons, així com als ajudants d'aquest, Juan i Juan Ignacio, pel seu tarannà sempre colllaborador durant la recerca. 
Key words:

Guillermus de Podio; Guillem Molins; Ars musicorum; Music theory; Cathedral of Barcelona; John II of Aragon; Cathedral of Valencia; Singer; Master of chant.

\section{Resumen:}

Bajo el nombre de autor de Guillermus de Podio se conservan dos obras de teoría musical de finales del siglo xv: la impresa Ars musicorum (Valencia, Hagenbach y Hutz, 1495) y el manuscrito Enchiridion de principiis musice discipline contra negantes illa et destruentes. A pesar de la gran influencia que este músico ejerció sobre los teóricos españoles del siglo XVI, son mínimos los datos biográficos generalmente aceptados por la comunidad investigadora. El presente artículo pretende ofrecer unos cimientos sólidos sobre los cuales poder construir su biografía. Con esta finalidad, se distinguen primeramente los datos contrastados de los que forman parte de la especulación en la historiografía del músico. Finalmente se aportan nuevos documentos que resuelven las dudas sobre su identidad y desvelan su magisterio en la catedral de Valencia.

Palabras clave:

Guillermus de Podio; Guillem Molins; Ars musicorum; Teoría musical; Catedral de Barcelona; Juan II de Aragón; Catedral de Valencia; Cantor; Maestro de canto.

If his influence among Spaniards was so much greater than Ramos's, why is so little known concerning his life?

Robert Stevenson (1987)

\section{INTRODUCCIÓ}

L'onze d'abril de 1495 eixia de les premses valencianes dels alemanys Peter Hagenbach i Leonhardt Hutz l'obra Ars musicorum o Commentariorum musices ${ }^{2}$, signada per Guillermus de Podio i finançada pel mercader llombard Jaume de Vila ${ }^{3}$. Una lleugera ullada a l'Ars Musicorum és suficient perquè ens adonem de la seua vocació universalista, gens comú en les obres teòriques hispanes de l'època, a excepció de

1 Vid. Stevenson, Robert: "Spanish musical impact beyond the Pyrinees (1250-1500)", a España en la Música de Occidente, Actes del Congrés Internacional celebrat a Salamanca, del 29 d'octubre al 5 de novembre de 1985. Madrid, Instituto Nacional de las Artes Escénicas y de la Música, Ministerio de Cultura, 1987, p. 136.

2 En el foli IIr apareix Commentariorum musices, mentre que al darrer foli de la taula de continguts final (sense foliar) s'utilitza el títol Ars musicorum, forma amb la qual s'ha fet més coneguda aquesta obra i que emprarem d'ací en avant. N'hi ha dues edicions modernes completes en facsímil d'aquest imprès: Podio, Guillermus de: Ars musicorum, Giuseppe Vecchi (ed.). Bolonya, Arnaldo Forni Editore, 1975; ID.: Ars Musicorum. Madrid, Joyas Bibliográficas, 1976. Una edició moderna parcial és ID.: Ars musicorum, Libri vI et VIII, Albert Seay (ed.). Colorado Springs, Colorado College Music Press, Critical Texts, núm. 8, 1978. Segons les dades de RISM, es conserven exemplars de l'obra a: $\boldsymbol{D}-S ; \boldsymbol{E}-\boldsymbol{M n} ; \boldsymbol{E}-\mathrm{PAp} ; \boldsymbol{E}-S ; \boldsymbol{E}-\mathrm{Tc} ; \boldsymbol{G B}-\mathrm{Cu} ; \boldsymbol{G B}-\mathrm{Lbm} ; \boldsymbol{I}-B c ; \boldsymbol{S}-U u$ [LESURE, François (ed.): Écrits imprimés concernant la musique, vol. I. München-Duisburg, Henle Verlag, 1971, p. 264].

3 La societat formada pel mercader Vila i els impressors Hagenbach i Hutz va dur a terme també la publicació dels Furs nous l'any 1493 i de tres llibres més fins al 1495. Sobre les activitats d'aquests personatges es pot consultar SERRANO MoraLES, José Enrique: Reseña Histórica en forma de diccionario de las Imprentas que han existido en Valencia desde la introducción del arte tipográfico hasta el año 1868 con noticias bio-bibliográficas de los principales impresores. València, Imprenta de F. Domènech, 1898-1899. 
Musica Practica ${ }^{4}$ del seu corresponsal epistolar Bartolomé Ramos de Pareja (*1440c; †1490p) ${ }^{5}$. Escrita íntegrament en llatí, Podio presenta l'obra dividida en vuit llibres que constitueixen un ampli compendi del saber musical de l'època, ja que es tracten des dels aspectes més filosòfics fins als més pràctics -cant pla, contrapunt i cant d'orgue-. Ars musicorum té l'honor, a més, de ser el primer llibre de teoria musical imprès als regnes hispànics on es tracta de polifonia. Al Museo internazionale e biblioteca della musica (abans Civico Museo Bibliografico Musicale) de Bolonya es conserva de forma manuscrita una altra obra amb el mateix nom d'autor, titulada Enchiridion de principiis musice discipline contra negantes illa et destruentes, estructurada en un pròleg i trenta-sis títols ${ }^{6}$. L'Enchiridion està dedicat al cabiscol de la seu de València Joan de Vera ${ }^{7} \mathrm{i}$ fou escrit en època molt propera a l'Ars musicorum, o poc després ${ }^{8}$. A més d'aquests dos tractats amb atribució expressa, es conserven tres escrits teòrics de menor extensió amb diferent grau de vinculació textual amb l'Ars musicorum. Dos d'aquests, redactats respectivament en castellà $-\mathrm{amb}$ insercions llatines- ${ }^{9}$ i en català ${ }^{10}$, són versions molt properes al llibre vII, sobre el cant men-

4 Es coneixen dues edicions d'època de l'obra: Bolonya, [Enrico de Colonia?], 11 de maig del 1482; Bolonya, Baltasar de Hiriberia, 5 de juny del 1482 . Es conserva un exemplar de la primera edició a $\boldsymbol{I}$ - $B c$ (hi manca el foli 1 ) i dos de la segona: $\boldsymbol{D}$ - $R p$ (incomplet) i a I-Bc (hi manquen els folis 1 i 23) [LESURE, François (ed.): op. cit., vol. II, p. 687]. Les edicions modernes de l'obra són nombroses i esmentarem només les editades a Espanya: RAMOs DE PAREJA, Bartolomé: Musica Practica, Rodrigo de Zayas (ed.), trad. per José Luis Moralejo. Madrid, Editorial Alpuerto, 1977; ID.: Musica Practica. Madrid, Joyas bibliográficas, 1983; ID.: Música Práctica, Clemente Terni (ed.), trad. per Gaetano Chiappini. Madrid, Joyas bibliográficas, 1983.

5 La relació de Podio amb Ramos és coneguda, curiosament, a través de l'obra d'un tercer tractadista, el carmelità anglès John Hothby, qui en la seua obra Excitatio quaedam musicae artis per refutationem (sense datar) rebat alguns paràgrafs d'un escrit desconegut de Ramos en què l'andalús es recolza per defensar algunes idees en una carta que li havia enviat "Guilielmus etiam Podius" [ОстовI, Johannis: Tres Tractaluti contra Bartholomeum Ramum, Albert Seay (ed.). Roma, American Institut of Musicology, 1964, pp. 22-23].

6 I-Bc, ms. A.71, pp. 134-190. Una edició moderna de l'obra pot trobar-se a GüMPEL, Karl-Werner: "Das Enchiridion de principiis musice discipline des Guillermus de Podio”, a Spanische Forschungen der Görresgesellschaft, 27 (1973), pp. 359-396. D’ací en avant em referiré a aquesta obra simplement com a Enchiridion de principiis musice discipline, o amb el més abreviat Enchiridion.

7 Joan de Vera va nàixer a Alzira el 1453. Doctor en dret, va ser preceptor de Cèsar Borja, fill del papa Alexandre vi, i va ocupar diversos càrrecs a la seu de València. Fou sotmès a un procés per una suposada conducta escandalosa que va concloure l'any 1498 sense conseqüències. L'any 1500 es va traslladar a Roma i el mateix any va ser nomenat arquebisbe de Salern i cardenal. L'any 1503, després de la mort d'Alexandre vI, va haver-hi un intent de Cèsar Borja d'elevar Joan de Vera al papat que no prosperà. Des del mateix any, Vera va rebre diverses prebendes a Burgos, Lleida i Saragossa, i el bisbat de Lleó, del qual no arribà a prendre possessió. Va morir a Roma l'any 1507. Per a més informació sobre la seua biografia, vegeu GoÑI, J.: "Vera, Juan”, a Quintín Aldea Vaquero, Tomás Marín Martínez i José Vives Gatell (eds.), Diccionario de Historia Eclesiástica de España, vol. IV. Madrid, Instituto Enrique Flórez, csic, 1973, p. 2732-2733; Hinojosa Montalvo, José: "Vera, Juan", a Diccionario de Historia Medieval del Reino de Valencia, vol. 4. València, Biblioteca Valenciana, 2002, pp. 358-359.

8 Pel que fa a la datació, s'ha de considerar que l'obra està dedicada a Joan de Vera com a cabiscol de la seu valenciana. El 23 de juny de 1492, aquest càrrec de dignitat capitular estava encara en poder de Joan de Borja $[\boldsymbol{E}$-VAc, not. Jaume Esteve, núm. 3686, protocols dels anys 1491-1493, 23 de juny de 1492], qui el gaudia des de l'any 1481 [Pons Alós, Vicente i M. Milagros CÁrCEl OrTí: "Los canónigos de la Catedral de Valencia (1375-1520). Aproximación a su prosopografía", a Anuario de Estudios Medievales, 35:2 (2005), p. 923]. El 27 de setembre de 1494 ja es té constància que Vera ocupava la dignitat de cabiscol de la seu i és bastant possible que rebera el càrrec després del capítol pasqual del 22 d'abril del mateix any, ja que encara no apareix en aquesta data relacionat en l'acta i sí que ho està en les posteriors [ $\boldsymbol{E}$-VAc, not. Jaume Esteve, núm. 3687, protocols 1494-1499, 27 de setembre de 1494; $\boldsymbol{E}$-VAc, not. Jaume Esteve, núm. 3605, Actes del Capítol 1480-1506, 22 d'abril de 1494]. En l'Enchiridion l'autor fa referència en diverses ocasions a l'Ars musicorum. No obstant això, aquest fet no significa necessàriament que la primera fos escrita després de la impressió de la segona (11 d'abril de 1495), ja que no s'hauria de descartar l'existència de redaccions prèvies en manuscrit d'aquesta darrera.

9 I-Bc, ms. A.71, pp. 191-207. Aquest escrit està editat a ANGLÈs, Higini: "La notación musical española de la segunda mitad del siglo xv. Un tratado desconocido de Guillermus... de Podio", a Anuario Musical, 2 (1947), pp. 151-173.

$10 \boldsymbol{E}$-Bbc, Ms. 1325, fols. 14r-19r. La transcripció íntegra d'aquest escrit i una descripció del manuscrit on es troba pot consultar-se a GüMPEL, Karl-Werner: "Eine Katalanische version der mensurallehre des Guillermus de Podio", a Orbis Musicae, 2 (1973-74), pp. 41-52. 
sural. El tercer, escrit en castellà i llatí, presenta una relació bastant més difusa amb l'imprès valenciàa ${ }^{11}$. Ja fora del terreny musical, és molt més hipotètica l'atribució, per part de Francisco Asenjo Barbieri (*1823; $\dagger 1894)$, d'un escrit teològic que, amb el títol Guillermus de Podio libellus disputationis contra incredulitatem editus Judeorum, es conservava l'any 1572 a l'església de Mondoñedo segons un antic inventari ${ }^{12}$.

Des de la nostra perspectiva actual, la rellevància de la figura de Guillermus de Podio es manifesta, fonamentalment, en dos aspectes: la preeminent influència que la seua obra va exercir sobre els teòrics hispànics del segle XVI -el ressò de la qual va arribar fins i tot al segle XVIII- ${ }^{13}$, i la seua presència freqüent en els estudis contemporanis sobre música en l'edat mitjana i el Renaixement, en especial en els que tracten de teoria de la música ${ }^{14}$. L'interès de la seua obra i la conseqüent necessitat de contextualització d'aquesta han propiciat que les qüestions al voltant de la biografia de Guillermus de Podio hagen estat ben presents en els treballs musicològics ja des del segle XIX, encara que, davant l'absència de documents inequívocs del music, alguns autors han optat per la formulació d'hipòtesis o teories en relació a certs aspectes com ara la identitat, el seu nom o origen. Malgrat tot, la realitat és que fins ara es disposa d'un mínim volum de dades biogràfiques acceptades de forma unànime per la comunitat musicològica com a pertanyents al tractadista.

En el present article es pretén fixar les bases inicials per a la construcció d'una biografia de l'autor. Com a primer pas, es tractarà d'oferir un panorama del coneixement actual biogràfic d'aquest influent music on es distingiran les dades documentades de les dades hipotètiques que han plantejat diversos autors ${ }^{15}$. En

11 I-Bc, ms. A.71, pp. 266-276. Valerie O'Donoghue el considera un resum del llibre v de l'Ars musicorum [O'DonOGHUE, Valerie Weinhouse: A music manuscript from the Spanish College of Bologna: A study of the Manuscript Bologna, Civico Museo Bibliografico Musicale, MS A 71 (olim 159). Tesi. University of Illinois at Urbana-Champaign, 1972].

12 Casares Rodicio, Emilio (ed.): Legado Barbieri, vol. 1. Madrid, Fundación Banco Exterior, 1988, p. 381.

13 Referències a l'autoritat de Guillermo poden trobar-se als següents tractats: Martínez DE Bizcargui, Gonzalo: Arte de canto llano y contrapunto y canto de órgano con proporciones y modos. Burgos, Fadrique Alemán de Basilea, 1509; edicions modernes: Madrid, Joyas Bibliográficas, 1976; Colorado Springs, Colorado College Music Press, 1979; Tovar, Francisco: Libro de Música Práctica. Barcelona, Johan Rosebach, 1510; edició moderna: Madrid, Joyas Bibliográficas, 1976; EsPinosa, Juan de: Tractado de principios de música práctica y teórica sin dejar ninguna cosa atrás. Toledo, Arnao Guillem de Brocar, 1520; edició moderna: Madrid, Joyas Bibliográficas, 1978; Bermudo, Juan: Declaración de instrumentos musicales. Osuna, Juan de León, 1555; edicions modernes: Kassel, Basilea: Bärenreiter, 1957; Madrid, Arte Tripharia, 1982; VillafrancA, Luis de: Breve introducción de canto llano. Sevilla, Sebastián Trujillo, 1565; Montanos, Francisco de: Arte de Música theórica y práctica. Valladolid, Diego Fernández de Córdoba y Oviedo, 1592; Cervera, Juan Francisco: Arte y Summa de canto llano. València, Pedro Patricio Mey, 1595; Cerone, Pedro: El Melopeo y Maestro. Nàpols, Juan Bautista Gargano i Lucrecio Nucci, 1613; edicions modernes: Bologna, Forni Editore, 1969; Antonio Ezquerro Esteban (ed.), Barcelona, Institució "Milà i Fontanals", CSIC, 2007; MonSERRATE, Andrés de: Arte Breve, y compendiosa de las dificultades que se ofrecen en la música práctica de canto llano. València, Pedro Patricio Mey, 1614; Arellano, Juan Salvador de: El Psalterio de David. Jerez de la Frontera, Fernando Rey, 1632; Cruz Brocarte, Antonio de la: Médula de la música theórica. Salamanca, 1707.

14 Es poden esmentar, com a exemples: ANGLÈs, Higini: "La notación musical...", op. cit., pp. 151-173; STEVENSON, Robert: Spanish Music in the Age of Columbus. The Hague, Martinus Nijhoff, 1960, pp. 73-82; León Tello, Francisco: Estudios de Historia de la Teoría Musical. Madrid, csic, 1961; O’Donoghue, Valerie Weinhouse: A music manuscript..., op. cit.; GümPel, Karl-Werner: "Das Enchiridion ...", op. cit, pp. 359-396; ID.: "Eine Katalanische...", op. cit., pp. 41-52; SerRANo VELASCO, Ana, M. Pilar SAuco Escudero, Juan D. MarTín SANZ et al.: Estudios sobre los teóricos españoles de canto gregoriano de los siglos XV al XVIII. Madrid, Sociedad Española de Musicología, 1980; Russell Williams, David i C. Matthew Balensuela: Music theory from Boethius to Zarlino. Hillsdale, NY, Pendragon Press, Harmonologia, 14, 2007.

15 Com que la finalitat d'aquest article no és oferir una biografia, no es subministraran exhaustivament totes les dades que actualment no estan contrastades ni són d'acceptació general, és a dir, les que proporcionen els autors que plantegen hipòtesis. No obstant això, en aquests casos es proporcionaran sintetitzades i, al mateix temps, s'oferirà la bibliografia on es troba la informació detallada. 
segon lloc, s'aportaran nous documents que aclariran definitivament la qüestió fonamental de la identificació de l'autor i que, per tant, permetran caminar sobre una base ferma en l'edifici biogràfic.

\section{LA QÜESTIÓ BIOGRÀFICA DE GUILLERMUS DE PODIO EN LA HISTORIOGRAFIA}

\section{LA FONT COMUNA: LES OBRES}

La revisió bibliogràfica sobre la biografia de l'autor ens ha mostrat que la totalitat de les escassíssimes dades comunament acceptades en la historiografia procedeixen de les mateixes dues obres de teoria musical conservades amb el nom de l'autor. A partir d'aquestes fonts directament, coneixem la seua ordenació eclesiàstica de prevere ${ }^{16} \mathrm{i}$ l'origen hispànic ${ }^{17}$, les quals han sigut les úniques dues premisses que no ha posat mai en dubte cap biògraf.

\section{UN VALUÓS DOCUMENT OBLIDAT}

Malauradament ha sigut gairebé totalment ignorat pels autors un interessant document publicat el $1986^{18}$. Es tracta d'una acta notarial que conté les capitulacions per a la construcció de dos orgues a l'església parroquial de Sant Tomàs de València, concordades en aquesta ciutat el 15 de juliol de 1489, per la qual es nomenava "mossèn Podio, prevere mestre de cant" com un dels experts visuradors dels treballs ${ }^{19}$. El lloc i la data del document, així com la condició de prevere mestre de cant d'aquest personatge, el convertien en un candidat amb una alta probabilitat d'identificar-se amb el tractadista, ja que, només sis anys més tard, es publicaria a la mateixa ciutat l'Ars musicorum.

\section{HIPÒTESIS I CREENCES}

Davant la manca de documentació d'època d'inequívoca pertinença a l'autor, la resta de qüestions sobre la seua personalitat tractades pels diversos biògrafs s'han plantejat en forma d'hipòtesis, malgrat que en ocasions s'haja fet el perillós pas de considerar-les com a fets certs i provats. Com a tal matèria especulativa, aquestes qüestions han estat proclius a les diferències entre els autors.

16 En el començament d'ambdós tractats apareix l'expressió "Guillermi de Podio, presbiteri”.

17 L'autor ho reconeix a l'Enchiridion en expressions com ara "nostre Hispanie" [I-Bc, ms. A.71, títol 25è, p. 172].

18 Una excepció n'és Ros Pérez, Vicent: "El Renacimiento", a Gonzalo Badenes Masó (ed.), Historia de la Música de la Comunidad Valenciana. València, Editorial Prensa Alicantina, Editorial Prensa Valenciana, 1992, p. 136.

19 “ $[\ldots]$ E per que nos puixa seguir entre les dites parts diferència alguna en la electió de les persones qui han de conèxer, judicar e arbitrar si los dits dos orgues seran be acabats e affinats segons dessus es contengut, ara per lavors e lavors per ara les dites parts son acordes que sien conexedors e examinadors de la primor e bondat dels dits orgues e dels gran e del xich e de totes les coses en que los dits mestre Johan Alamany e en Ponç son tenguts e obligats juxta los dits capítols sobredits los venerables mossèn Podio, prevere mestre de cant, mossèn Noffre, sonador del orgue de la Seu e mestre Formen, mestre de orguens [...]" [E-VAar, protocols notarials, not. P. J. Zabrugada, prot. núm. 3064, 15 de juliol de 1489. Fragment pres de la transcripció íntegra del document oferida a NicolaU BAUZÀ, P. Josep: "Un orgue per a la parròquia de Sant Tomàs de València (1489)", a Cabanilles, 17 (gener-març de 1986), p. 14]. 
Les divergències dels biògrafs comencen per la mateixa identitat del músic. Sobre aquesta qüestió s'han plantejat un parell de teories per les quals s'identifica el tractadista amb personatges dels quals es coneixen algunes dades:

- Guillem Puig, beneficiat en la parròquia de Santa Caterina d'Alzira. La identificació de Guillermus de Podio amb aquest personatge va ser proposada amb molta decisió per J. Ruiz de Lihory el 1903, qui va proporcionar, a més, diverses dades relatives al seu benifet en aquesta ciutat valencia$\mathrm{na}^{20}$. No obstant això, aquest autor no va aportar cap informació definitiva que relacionés aquest eclesiàstic amb activitats musicals i que pogués impulsar de manera més ferma aquesta hipòtesi. Segurament per aquesta raó, la identificació no ha sigut, en general, acceptada ${ }^{21}$.

- Guillem Molins de Podio, mestre de cant de la catedral de Barcelona i músic de la capella del rei Joan II d'Aragó. L'any 1947 Higini Anglès va plantejar per primera vegada, encara que indirectament, la possibilitat que hi pogués haver alguna relació entre Guillermus de Podio, tractadista, i un cert "Guillermo Molins de Podio", del qual en aquell moment només es coneixia la condició de capellà de Joan II el 1474 a través de dos documents per a la seua presentació i col-lació al segon benifet de Sant Blai de la seu de Barcelona ${ }^{22}$. Simptomàticament, Anglès va introduir uns significatius punts suspensius en el títol del seu treball: "La notación musical española de la segunda mitad del siglo xv. Un tratado desconocido de Guillermus... de Podio"23. La idea d'aquesta identificació va ser represa als anys vuitanta per Josep Maria Gregori, qui va exposar obertament la possibilitat que els dos personatges, tractadista i capellà, fossen una mateixa persona ${ }^{24}$. El mateix autor ha fet un pas endavant en els treballs posteriors en no manifestar cap dubte sobre la identificació, malgrat que no s'hagen publicat documents definitius que la proven ${ }^{25}$. Val a dir que Gregori ha fet una tasca valuosa de recopilació de dades per a la biografia de Guillem Molins de Podio que es trobaven disperses en

20 Vid. Ruiz de Lihory, José: La Música en Valencia. Diccionario biográfico y crítico. València, Establecimiento Tipográfico Doménech, 1903, p. 378.

21 No obstant això, R. Stevenson no expressa cap reserva pel que fa a la fiabilitat de la informació de Ruiz de Lihory a STEVenson, Robert: "Spanish musical impact...", op. cit., p. 136.

22 Arxiu Diocesà de Barcelona, Liber Colationum, vol. 72, fols. 115r-115v, 29 de juny de 1474; ibid., 116r-116v, 29 de juny de 1474. L'existència d'aquests documents, descoberts per Jaime Moll, va ser assenyalada per primera vegada dins d'ANGLÈs, Higini: "La notación musical...", op. cit., p. 158. Anglès va escriure sobre això: "Nos es difícil señalar qué relación pueda tener nuestro autor con aquel Guillermo Molins de Podio, beneficiado de la catedral de Barcelona, al cual Juan II de Aragón (†1479) proponía por capellán de su real capilla de Barcelona, en 1474” [ibíd, p. 158].

23 Ibid., p. 151.

24 Vid. Gregori i Cifré, Josep Maria: "Mateu Ferrer, tenorista i mestre de cant de la Seu de Barcelona (1477-1498)", a Recerca Musicològica, III (1983), p. 11; ID.: "Pere Alberch, artífex de la relació musical entre les seus de Girona i Barcelona en el Renaixement tardà", a Annals de l'Institut d'Estudis Gironins, 28 (1985-1986), pp. 281-282.

25 Vid. Gregori i Cifré, Josep Maria: "El Renaixement musical hispànic en les aportacions posteriors a Higini Anglès, 1970-1987“, a Recerca Musicològica, IX-X (1989-1990), p. 159; ID.: "Músics de la Capella Reial catalano-aragonesa de Joan II i de Ferran II a la catedral de Barcelona (1418-1514)", a Butlletí de la Societat Catalana de Musicologia (1995), pp. 21-23; ID.: "La Música del Renaixement", a Història de la cultura catalana, vol. II. Barcelona, Edicions 62, 1997, pp. 244-245; ID.: "Renaixement i manierisme", a Francesc Bonastre (ed.), Història crítica de la Música Catalana. Barcelona, Institut de Musicologia "Josep Ricart i Matas", Universitat Autònoma de Barcelona, 2009, pp. 63-64. A partir d'aquesta acceptació de la identificació, Gregori ha plantejat la hipòtesi d'un viatge a Itàlia del tractadista al voltant de 1480 [ID.: "El Renaixement...", op. cit., p. 159]. 
diverses publicacions, algunes de llunyanes a l'àmbit musicològic ${ }^{26}$. Gràcies a aquest treball, s'han fet conegudes les estades d'aquest músic com a mestre de cant a la seu de Barcelona (almenys durant el període 1446-1458), com a cantor de la capella de Joan II (almenys el 1470) i mestre d'aquesta capella (1474-1475?), com també la possessió d'una plaça de prevere de capítol a la seu de Girona (almenys durant l'interval 1470-1478) i del benifet de Sant Blai a la seu de Barcelona (1474), institucions totes on la resta de documentació coneguda el cita simplement com a "Guillem Molins". Malgrat tot, les dades aportades per Gregori no inclouen referències a l' activitat de Guillem Molins com a teòric musical ni a la seua relació amb València, on Guillermus de Podio va publicar el 1495 l'Ars Musicorum. Segurament per aquest motiu fonamental, encara que també per la gran diferència temporal entre el seu magisteri en la seu de Barcelona (almenys des de 1446) i les seues obres (després de 1495), i perquè el cognom Molins no apareix en cap d'aquestes, la identificació del tractadista Guillermus de Podio amb el músic Guillem Molins de Podio no ha sigut comunament acceptada ${ }^{27}$.

La forma en llengua romanç del nom del tractadista també ha sigut objecte de diferències entre els autors. L'única dada de partida és la forma llatinitzada Guillermus de Podio, la qual apareix en totes dues obres teòriques de l'autor. Diversos cognoms catalans d'origen semblant -com ara Despuig [o Dezpuig], Puig, de Puig o del Puig- prenen la forma de Podio quan s'escriuen en llatí. Els dos primers han sigut utilitzats per a referir-se al músic.

- Despuig. Ha sigut l'utilitzat pel corrent més estès en la historiografia musical des del segle XIX. Així, s'ha adoptat molt sovint el nom complet de Guillem Despuig, o fins i tot la variant castellana Guillermo Despuig per referir-se al tractadista. El primer musicòleg de què tenim coneixement que va fer servir la forma Despuig és Francisco Asenjo Barbieri, qui va escriure "Guillermo Despuig, de una familia noble de Tortosa" en una nota breu sobre el vers del foli de guarda anterior al primer full imprès de l'exemplar de l'Ars Musicorum que es conserva a la Biblioteca Colombina, a Sevilla ${ }^{28}$.

26 El resultat d'aquest treball es pot trobar en les publicacions citades anteriorment, com també a: GrEGORI I CiFRé, Josep M.: La Música del Renaixement a la Catedral de Barcelona, 1450-1580. Tesi doctoral. Bellaterra, Publicacions de la Universitat Autònoma de Barcelona, 1987, p. 13; ID.: "Jaume Castelló, un cantor de la Capella Reial de Joan II present en el setge de la Força de Girona del 1462", a Annals de l'Institut d'Estudis Gironins, 34 (1994), p. 80. Les fonts amb informació recopilada per Gregori són, fonamentalment: MAs, Josep: "Nota històrica. Taula dels Mestres del Cant, o de Capella, de la Seu de Barcelona", a El Correo Catalán (25 de desembre de 1917), p. 2; Madurell, José M.: "Documentos para la Historia de los Maestros de capilla, cantores, organistas, órganos y organeros. Siglos Xiv-XVIII", a Anuario Musical, 6 (1951), p. 206; Civil Castellví, Francisco: "Personajes y aconteceres musicales", a Revista de Girona, 58 (primer trimestre de 1972), p. 79.

27 Com a exemple, les veus més recents que corresponen a Guillermus de Podio al New Grove Online, Diccionario de la Música Española e Hispanoamericana i al Die Musik in Geschichte und Gegenwart presenten aquesta identificació com una simple hipòtesi. En els dos primers casos, a més, també s'esmenta la de Ruiz de Lihory sense manifestar-se cap preferència. [LEÓN Tello, Francisco: "Podio [Puig]; Guillermo de [Despuig, Guillermo]", a Grove Music Online, L. Macy (ed.) (consulta: 21 de març de 2010), <http://www.grovemusic.com>; MARTín GALÁN, Jesús: "Podio [Puig], Guillermo de [Guglielmus de] [Guillermo Molins Despuig]", a Emilio Casares Rodicio (ed.), Diccionario de la Música Española e Hispanoamericana, vol. 8. Madrid, Sociedad General de Autores y Editores, 2001, pp. 867-868; GüMPEL, Karl-Werner: "Guillermus de Podio, Guillem Despuig", a Die Musik in Geschichte und Gegenwart, Personenteil, vol. 8. Stuttgart, Bärenreiter-Verlag, 2002, cols. 249-251].

28 Cabildo catedral de Sevilla. Biblioteca Colombina, $\boldsymbol{E}-S, 15-5-17$, s. f. L'existència d'aquesta anotació de Barbieri ja va ser observada per H. Anglès [ANGLÈs, Higini: "La notación musical...", op. cit., p. 160]. 


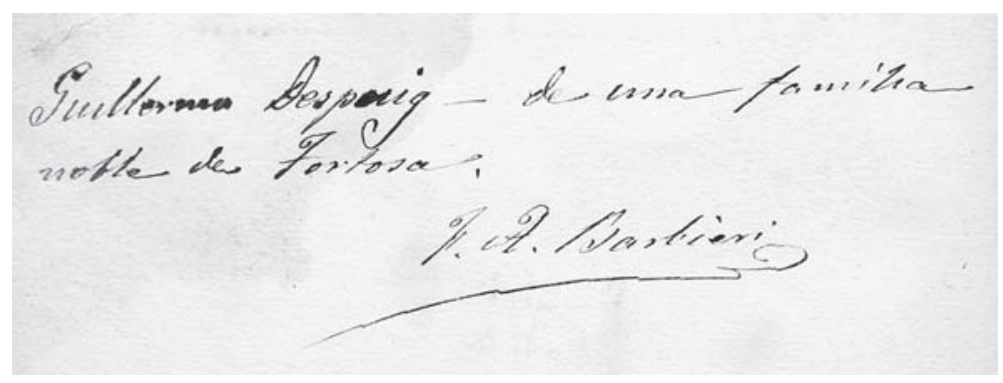

Figura 1. Nota de Francisco Asenjo Barbieri [E-S, 15-5-17, s. f.].

Si hem de jutjar per la semblança de contingut, aquesta anotació de Barbieri està segurament basada en una altra, d'autor anònim, que apareix en un dels exemplars de l'Ars Musicorum conservats, en aquest cas a la Biblioteca Nacional d'Espanya, amb el text "Guillermo Despuyg, familia antigua, y noble de Tortosa" ${ }^{29}$. La idea d'un suposat origen noble del tractadista, no massa secundada pels seus predecessors, provindria també de la còpia no literal d'aquesta nota per part de Barbieri ${ }^{30}$. Malgrat tot, s'ha d'observar que la cal-ligrafia d'aquesta darrera anotació marginal sembla anterior al segle XIX, en què visqué Barbieri, però també bastant posterior a l'època del tractat, per la qual cosa potser no hauria de valorar-se en excés la credibilitat de la seua informació.

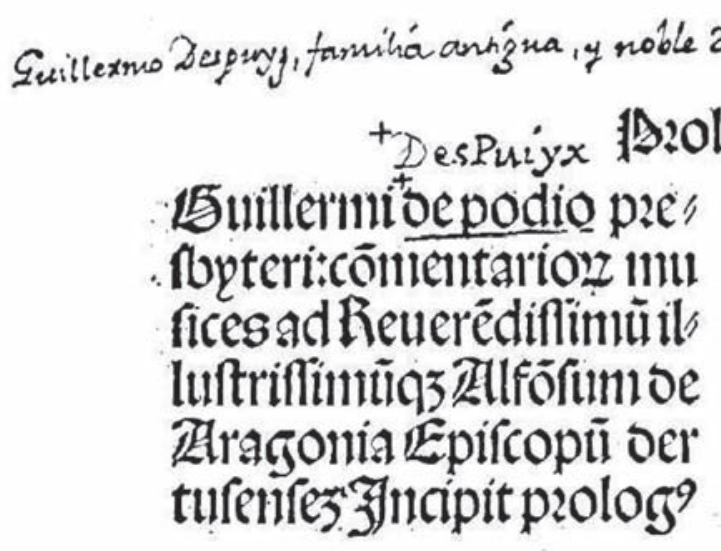

Figura 2. Nota marginal anònima [E-Mn, I/1518, f. IIr.].

$29 \boldsymbol{E}-M n$, I/1518, f. IIr. La mateixa font no és regular en l'ortografia, ja que sobre el nom d'autor de l'imprès "de Podio" apareix una altra anotació "DesPuiyx", la qual, però, podria ser de diferent mà.

30 Pot interpretar-se que en la nota d' $\boldsymbol{E}-\mathbf{M n}$, no es diu que el tractadista pertanguera necessàriament a aqueixa família noble tortosina, com assevera Barbieri en la seua nota, sinó que amb el cognom Despuig hi existeix una antiga família noble a Tortosa. 
Probablement, en el procés de consolidació d'aquesta forma Despuig va tenir bastant influència la decisió de Marcelino Menéndez y Pelayo, qui, segurament per influència del seu assessor musical Barbieri, va emprar-la també en la seua transcendental i influent obra Historia de las ideas estéticas en España (1884-1891) ${ }^{31}$. Molts altres autors posteriors varen seguir els passos de Menéndez y Pe$\operatorname{layo}^{32}$.

- Puig. Aquesta opció és la que va defensar José Ruiz de Lihory en basar-se en els documents que va fer servir per a formular la seua hipòtesi d'identificació ja esmentada amb Guillem Puig, beneficiat d'Alzira. La proposta no ha tingut a penes seguidors ${ }^{33}$.

Un darrer assumpte sobre el qual s'han constatat divergències ha sigut el de l'origen o procedència geogràfica del músic, malgrat que cap hipòtesi plantejada per resoldre aquesta qüestió no ha eixit de l'àmbit de l'antiga Corona d'Aragó, i més en concret el dels seus territoris al regne de València i a Catalunya. Sobre aquest aspecte s'han plantejat tres hipòtesis:

- Origen valencià. Va ser assumit directament per José Ruiz de Lihory ${ }^{34}$, a qui seguiren Rafael Mitjana $^{35}$, Josep Subirà ${ }^{36}$ i Higini Anglès ${ }^{37}$, amb diferents graus de convenciment. En principi, cap d'aquests autors no va aportar arguments que sostinguessen aquesta possibilitat. Més tard, Anglès va recolzar en la dedicatòria de l'Enchiridion a Joan de Vera, destacat membre del capítol valencià, com també en la publicació de l'Ars Musicorum en aquesta mateixa ciutat, malgrat que certament

31 Vid. Menéndez y Pelayo, Marcelino: Historia de las ideas estéticas en España, vol. 1. Madrid, csic, 1994; 1a edició: Madrid, A. Pérez Dubrull, 1883, pp. 939-940, 945-950, 952.

32 L'any 1897, Pedrell només ho planteja com una possibilitat: "Despuig (Guillermo): Es probable que este apellido fuera el real y verdadero del antiguo tratadista llamado Guillermo de Podio." [PeDrell, Felip: Diccionario Biográfico y bibliográfico de músicos y escritores de música españoles, portugueses é hispano-americanos antiguos y modernos: acopio de datos y documentos para servir á la historia del arte musical en nuestra nación, vol. III. Barcelona, Víctor Berdós y Feliu, 1897, p. 481]. Però l'any 1909, Pedrell ja no dubta: "Podio (Guillem Despuig, dit de): 21, 346" [Pedrell, Felip: Catàlech de la Biblioteca Musical de la Diputació de Barcelona ab notes històriques, biogràfiques y crítiques, transcripcions en notació moderna dels principals motius musicals y facsímils dels documents més importants pera la bibliografía espanyola, vol. 2. Barcelona, Palau de la Diputació, 1909 , p. 359]. Uns quants exemples d'altres treballs destacables posteriors en què s'adopten aquestes formes són: MiTJANA, Rafael: La Música en España (Arte religioso y Arte Profano). Madrid, Centro de Documentación Musical, Instituto Nacional de las Artes Escénicas y la Música, Ministerio de Cultura, 1993; primera edició en francès: París, Libr. Delagrave, 1920, p. 47; ANGLÈs, Higini: La Música Española desde la Edad Media hasta nuestros días. Barcelona, Diputació Provincial de Barcelona, Biblioteca Central, 1941, p. 62; SubIRÁ, José: Historia de la Música, vol. I. Barcelona, Salvat, 1951, p. 346; ID.: Historia de la música española e hispanoamericana. Barcelona, Salvat Editores, 1953, p. 169; STEVEnSon, Robert: "Spanish musical impact...", op. cit., p. 135; Gómez Muntané, Maricarmen: “Despuig, Guillem [Podio, Guillem de]”, a Jesús Giralt i Radigales (ed.), Gran Enciclopèdia de la Música, vol. 2. Barcelona, Fundació Enciclopèdia Catalana, 2000, s.f.

33 Ruiz de LiHory, José: La Música en Valencia...., op. cit., pp. 377-378. En alguna ocasió, el mateix Anglès ha fet també servir aquesta forma [ANGLÈs, Higini: "El "Chansonier français" de la Biblioteca de la Colombina de Sevilla”, a José López-Calo (Ed.), Hygini Anglés. Scripta musicologica, III (Roma: Edizioni di Storia e Letteratura, 1975), p. 1387. Primera edició de l'article a Estudis Universitaris Catalans, XIV (1929), pp. 227-258].

34 Ruiz DE LiHory, José: op. cit., pp. 377-378

35 Vid. Mitjana, Rafael: La Música en España..., op. cit., p. 47.

36 Vid. SubiRÁ, José: Historia de la Música..., op. cit., p. 346; ID.: Historia de la música española..., op. cit., p. 169. p. 128 .

37 Vid. Anglès, Higini (ed.): La música en la Corte de los Reyes Católicos, I, Polifonía Religiosa. Barcelona, Csic, 1941, 
es va decantar per mantenir precaució ${ }^{38}$. Posteriorment, aquest autor encara adoptaria una postura més conservadora, en vincular el músic a València simplement com a lloc de residència, però sense atribuir-li un origen ${ }^{39}$. D' aquesta manera, Anglès tornava a una antiga opinió que havien compartit François Joseph Fétis ${ }^{40}$, Baltasar Saldoni ${ }^{41}$ o Felip Pedrell ${ }^{42}$.

- Origen tortosí. Aquesta hipòtesi, per la qual se suposaria que el tractadista era oriünd de Tortosa, va ser apuntada per F. A. Barbieri en la nota manuscrita que va escriure en l'exemplar de l'Ars musicorum de la Biblioteca Colombina, com ja s'ha exposat detalladament més amunt. Anglès va tractar-la com una possibilitat i va recolzar en una altra dedicatòria del músic -en aquest cas de l'Ars Musicorum - al bisbe de Tortosa, Alfons d'Aragó, sense reparar què aquest prelat no residia a Tortosa sinó a València en l'època d'aquesta publicació ${ }^{43}$.

- Origen gironí. La possibilitat d'una procedència gironina de Guillem Molins va ser formulada l'any 1972 per F. Civil. L'autor, a més, el va suposar d'ascendència nobiliària ja que hi havia, en una de les capelles de la catedral de Castelló d'Empúries, una inscripció sepulcral i un escut d'un "Guillerm Molins, prevere", mort el 1369, que Civil considerava pertanyents "sin duda alguna, a un su antecesor y homónimo" sense aportar cap dada que refermés aquesta afirmación ${ }^{44}$. S'ha de puntualitzar que Civil es referia en tot moment a Guillem Molins com a canonge de la seu de Girona i cantor de Joan II, però en cap cas no va associar aquest personatge al tractadista, ja que la identificació decidida dels dos personatges no es va produir fins a la dècada dels vuitanta en els treballs de J. M. Gregori, com ja s'ha indicat.

38 Vid. ANGLÈs, Higini: “La notación musical...”, op. cit., p. 158, 160.

39 Vid. Pena, Joaquín i Higini Anglès: Diccionario de la Música Labor, vol I. Barcelona, Editorial Labor, 1954, p. 714.

40 FÉTIs, François Joseph: Biographie universelle des musiciens et bibliographie generale de la musique, vol. VII. París, Firmin-Didot et Cie, $2^{\mathrm{a}}$ edició, 1878, p. 82. La primera edició d'aquesta obra està datada en 1835-1844.

41 Saldoni, Baltasar: Diccionario biográfico-bibliográfico de efemérides de músicos españoles, vol. 4. Madrid, Imprenta de Antonio Pérez Dubrull, 1881, p. 257.

$42 \boldsymbol{E}$-Bbc, M 942, "Documentos inéditos para su diccionario".

43 Vid. ANGLÈs, Higini: "La notación musical...", op. cit., p. 158. Alfons d'Aragó, nascut a València el 1455, va ser fill natural del primer duc de Villahermosa Alfons d'Aragó, fill també natural del rei Joan II. Va estudiar a la Universitat de Lleida i va ser una persona cultivada en les lletres. L'any 1475 va ser nomenat bisbe de Tortosa. Estava instal·lat a València de forma permanent a les acaballes de 1485, ciutat on va fer-se construir un palau al carrer de Cavallers, i des d'aquesta ciutat va governar la seua diòcesi. Al 1513 va ser promogut a l'arquebisbat de Tarragona. També va presidir la Generalitat Catalana durant el període 1500-1503. Es pot trobar més informació sobre Alfons d'Aragó, bisbe de Tortosa, i sobre el seu palau a València, a GómEZ-FERRER, Mercedes, i Juan Corbalán: "La casa del obispo de Tortosa, Alfonso de Aragón. Un palacio valenciano en la encrucijada entre dos siglos (xvXVI)", a Ars Longa, 13 (2004), pp. 11-31. Específicament sobre la biografia d'Alfons d'Aragó, es pot consultar dins FERNÁNDEZ DE Bethencourt, Francisco: Historia genealógica y heráldica de la monarquía española. Casa Real y Grandes de España, vol. III. Madrid, Establecimiento tipográfico de Enrique Teodoro, 1901, pp. 429-430.

44 Vid. Civil Castellví, Francisco: "Personajes...", op. cit., p. 59. 


\section{Altres dades no DOCUMENTADES}

Finalment, la revisió bibliogràfica ha permès trobar altres dades sense documentar per a la biografia del músic, diferents de les ja exposades i que no han sigut pràcticament considerades pels autors posteriors.

Algunes enciclopèdies generals subministren informacions de dubtosa credibilitat, mentre no es donen a conèixer les fonts de la informació. De manera contundent, l'autor de la veu "Despuig, Guillem" de la Gran Enciclopèdia Catalana afirma que el tractadista era beneficiat a la parròquia de Sant Joan del Mercat de València ${ }^{45}$. Per la seua part, l'autor de la veu "Despuig, Guillem" del Diccionari biogràfic Albertí, el considera, a més de "prelat i musicòleg" (!), també distingit jurista relacionat amb el rei d'Aragó Alfons el Magnànim, a més de mestre de capella a la catedral de València. Fins i tot, arriba a adjudicar-li un cardenalat ${ }^{46}$. Pel que fa a aquestes dades, s'ha de deixar clar que de cap manera el músic no va ser cardenal, però aquesta errada manifesta ens fa sospitar en una confusió del biògraf amb Joan de Vera -destinatari de la dedicatòria de l'Enchiridion-, qui fou arquebisbe de Salern, doctor en drets, cabiscol de la seu de València i cardenal, un perfil que encaixa notablement amb el que s'adjudica erròniament al tractadista.

Un lapsus semblant potser també pogué conduir H. Anglès a asseverar que el tractadista va estar molt relacionat amb els savis espanyols a Itàlia i, fins i tot, amb els que estaven al servei dels Borja a Roma $^{47}$, ja que una afirmació pareguda és aplicada en una altra ocasió a Joan de Vera pel mateix Anglès ${ }^{48}$. De qualsevol manera, l'autor tampoc no proporciona dades sobre els fonaments de la informació.

\section{LA VERTADERA IDENTITAT DE GUILLERMUS DE PODIO}

La meua recerca arxivística sobre la trajectòria vital de Guillermus de Podio ha possibilitat el discerniment definitiu de la seua vertadera identitat com un dels principals resultats, el discerniment definitiu de la seua vertadera identitat. El present capítol té com a objectiu l'exposició del procediment deductiu, basat en fonts arxivístiques, que resol qualsevol dubte.

Un primer document fonamental ens situa a València "Guillermus Molins, presbiter in ecclesia Valentina, beneficiatus de beneficio ibidem instituto sub honorificencia beati Jacobi Apostoli per serenissi-

45 Vid. Carbonell i de Ballester, Jordi i Joan Carreras i Martí (ed.): “Despuig, Guillem”, a Gran Enciclopèdia Catalana, vol. 9. Barcelona, Enciclopèdia Catalana, 1988-1989, p. 92. Les dificultats per a poder confirmar aquesta informació són notables, ja que l'arxiu parroquial de Sant Joan del Mercat (actualment anomenada dels Sants Joans) de València es va cremar el 1936, durant la Guerra Civil Espanyola.

46 "Despuig, Guillem. Prelat i musicòleg valencià del segle Xv. Fou també jurista distingit. Es relacionà amb Alfons IV [e]l Magnànim. Actuà de mestre de capella a la catedral de València. Fou nomenat cardenal. En 1495 fou imprès a València el seu Ars musicorum, obra que ha estat estudiada per mossèn Higini Anglès." [Albertí I Gubern, Santiago (ed.): "Despuig, Guillem”, a Diccionari biogràfic, vol. 2. Barcelona, Edicions Albertí, 1968, p. 32].

47 "Otro teórico conocido fué aquel Guillelmus de Podio, valenciano o tortosino, que estuvo muy relacionado con los sabios y artistas españoles al servicio del pontificado de los Borjas en Roma." [ANGLÈs, Higini: "Gloriosa contribución de España a la Historia de la Música Universal”, a José López-Calo (ed.), Hygini Anglés. Scripta musicologica, vol. II. Roma, EDIZIONI Di StORIA E LITTERATURA, 1995, p. 828; primera publicació: Madrid, CSIC, 1948].

48 "Págs. 134-190 sigue el tratado susodicho [Enchiridion] del valenciano Guillermo de Podio (=Despuig), dedicado al célebre Juan de Vera, primeramente canónigo de Valencia, quien formó parte de la corte de hombres sabios de Rodrigo de Borja, el cual, siendo Papa Alejandro vi, le nombró obispo de Palermo (sic) y más tarde Cardenal y legado de España" [AngLĖs, Higini (ed.): La música en la Corte..., op. cit., p. 128]. 
mum dominum nostrum, dominum Jacobum dive memorie, ac presbiter eciam de capitulo ecclesie Gerundensis", compareixent davant el notari Bartomeu Lloscos el 21 de març de 1480 ${ }^{49}$. Es tracta, sens dubte, de l'antic cantor del rei Joan II d'Aragó, perquè l'acta notarial fa al·lusió a la seua condició de prevere de capítol de la seu gironina, que la documentació fins ara coneguda del músic reial ja li atorgava almenys des de l'11 de març de $1470^{50}$. Per tant, després de la mort del seu patró Joan II, que tingué lloc el 19 de gener de 1479, el músic es trobava a València, on posseïa un benefici de patronat reial en la mateixa catedral, i acudia al notari per nomenar procuradors per gestionar, en el seu nom i davant l'arquebisbe de Saragossa o el seu vicari general, la permuta d'un benefici en l'església de Santa Engràcia de Saragossa i la vicaria perpètua de la Puebla de Alfindén, població propera a aquesta ciutat. Entre els tres procuradors nomenats, es troba Pedro Pifán, qui possiblement fos el mateix “maese Pifán”, músic, que va cobrar mig florí d'or per "tantos quinternos que fizo notados para cantar á los prophetas, á la Maria y Jesus" en la representació de la Nativitat que es va fer a la basílica del Pilar de Saragossa el 1487 davant els reis Catòlics ${ }^{51}$.
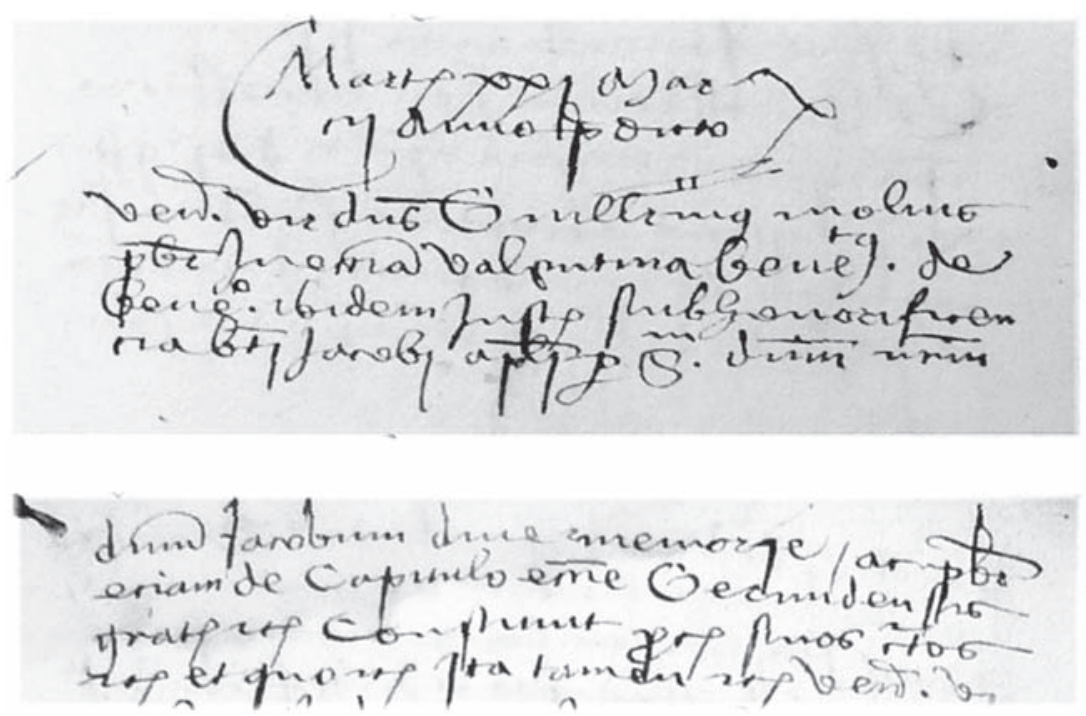

Figura 3. Detall de l'acta notarial de nomenament de procuradors [E-VAcp, núm. 21204, 21 de març de 1480] $]^{52}$.

$49 \boldsymbol{E}$-VAcp, protocols notarials, not. Bartomeu Lloscos, núm. 21204, 21 de març de 1480. Vegeu un detall del document a la figura 3. Vegeu-ne una transcripció i traducció completa a l'apèndix documental, doc. 1.

50 " [...] dilectus capellanus et cantor nostre capelle, sive continuus comensalis noster, Guillermus Molins, unus de duodecim praesbyteris de capitulo ecclesiae gerundense, ac unus de capitularibus eiusdem capituli [...]", ([...] dilecte capellà i cantor de nostra capella, o continu comensal, Guillem Molins, un dels dotze preveres de capítol de la seu de Girona, i un dels membres capitulars de dit capítol [...]), [E-Bac, Cancelleria Reial, registre núm. 3427, f. 138v-139v, 11 de març de 1470]. Aquest document està parcialment reproduït en traducció al castellà a Civil CAstellví, Francisco: "Personajes...", op. cit., p. 60. Alguns fragments de la transcripció del llatí original es poden trobar també a Gregori i Cifré, Josep Maria: "Músics de la Capella...”, op. cit., p. 21.

51 Vegeu la primera publicació de la dada, en GonZÁLEZ, José Fernando: Crónica de la provincia de Zaragoza, Madrid, Rubio y compañía, 1867, p. 48.

52 Vegeu transcripció i la traducció completa del document a l'apèndix documental, doc. 1. 
Però l'autor d'Ars musicorum, Guillermus de Podio, també donava mostres de la seua activitat a València en la mateixa època. A les actes dels anomenats capítols pasquals de la seu valenciana, que es celebraven anualment cap a finals d'abril, apareixen els noms, en llatí, de les persones que havien d'exercir els diversos oficis catedralicis durant el següent exercici ${ }^{53}$. En el període 1486-1499 he pogut constatar, en efecte, la presència de Guillermus de Podio en les actes com a rebedor del nomenament de "substitut" del canonge que tenia la titularitat en la regència de les escoles del cant, a qui en l'època s'anomenava generalment mestre de les escoles del cant o mestre de cant (vegeu la taula 1). Malgrat posseir les titularitats dels oficis, els canonges no exercien directament les funcions quan tenien substituts, sinó que les delegaven en aquests ${ }^{54}$. Per causes desconegudes, el 1494 no apareix en la corresponent acta el nom de Podio, ni el de cap altre substitut, i el 1496 hi figura esborrat i, sobre aquest, un afegit amb el nom d'Andrés de Soria. Malauradament no s'han pogut localitzar les actes dels capítols pasquals del període 1456-1485, per conèixer amb seguretat si exercia el càrrec des d'abans, ni tampoc la de l'any 1500.

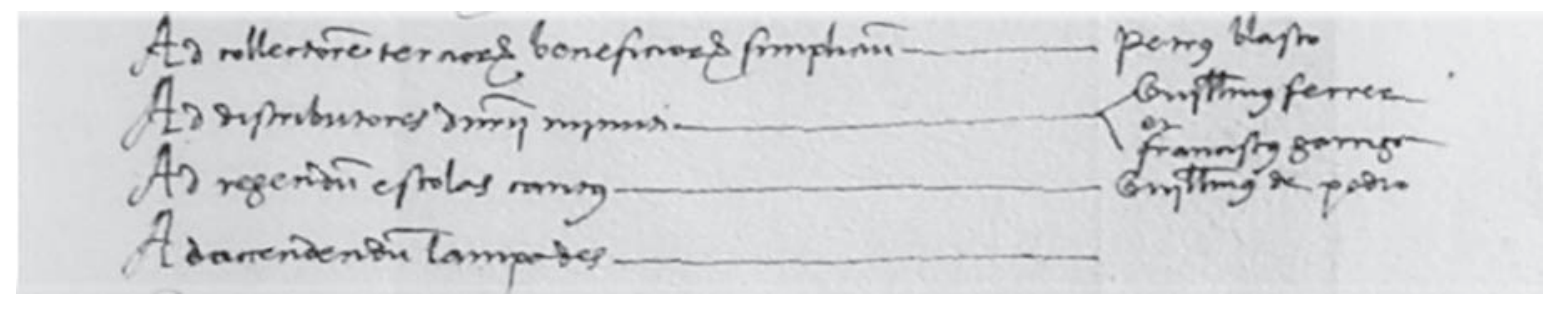

Figura 4. Detall de nomenament de substituts de 1499 [E-VAc, not. Jaume Esteve, núm. 3605, fol. 11r, 29 d'abril de 1499].

\begin{tabular}{|c|c|c|c|c|c|}
\hline Data & $\begin{array}{c}\text { Canonge rector de les } \\
\text { escoles del cant }\end{array}$ & Substitut & Notari & Vol. & foli \\
\hline 26-04-1486 & Mathias Mercader & Guillermus de Podio & Joan Esteve & 3596 & $10 \mathrm{v}-12 \mathrm{v}$ \\
\hline 28-04-1487 & Petrus Paulus Rossell & Guillermus de Podio & Joan Esteve & 3596 & $76 \mathrm{r}-78 \mathrm{r}$ \\
\hline 29-04-1488 & Petrus Paulus Rossell & Guillermus de Podio & Jaume Esteve & 3605 & $110 \mathrm{r}-110 \mathrm{v}, 117 \mathrm{r}$ \\
\hline 27-04-1489 & Mathias Mercader & Guillermus de Podio & Jaume Esteve & 3605 & $111 \mathrm{r}-111 \mathrm{v}, 116 \mathrm{r}$ \\
\hline 26-04-1490 & Petrus Paulus Rossell & Guillermus de Podio & Jaume Esteve & 3605 & $112 \mathrm{r}-112 \mathrm{v}, 115 \mathrm{r}$ \\
\hline 07-04-1491 & Petrus Paulus Rossell & Guillermus de Podio & Jaume Esteve & 3605 & $113 \mathrm{r}-114 \mathrm{r}$ \\
\hline 27-04-1492 & Petrus Paulus Rossell & Guillermus de Podio & Jaume Esteve & 3605 & $118 \mathrm{r}-119 \mathrm{v}$ \\
\hline 29-04-1493 & Petrus Paulus Rossell & Guillermus de Podio & Jaume Esteve & 3605 & $149 \mathrm{r}-150 \mathrm{r}$ \\
\hline
\end{tabular}

53 Aquests començaven el primer de maig i acabaven el 30 d'abril de l'any següent.

54 Vegeu Villanueva Serrano, Francesc: "Mateo Flecha, el Viejo, en la Catedral de Valencia: sus dos períodos de magisterio de capilla (1526-1531? y 1539-1541) y su entorno musical" a Anuario Musical, 64 (2009) pp. 80-81.

55 "Ad regendum escolas cantus - Guillermus de Podio". 


\begin{tabular}{|c|c|c|c|c|c|}
\hline 22-04-1494 & Petrus Paulus Rossell & Andreas de Soria & Jaume Esteve & 3605 & $151 \mathrm{r}-152 \mathrm{r}$ \\
\hline 30-04-1495 & Jacobus Conill & Guillermus de Podio & Joan Esteve & 3596 & $133 \mathrm{r}-133 \mathrm{v}, 138 \mathrm{r}$ \\
\hline 29-04-1496 & Martinus Enyego & - & Joan Esteve & 3596 & $134 \mathrm{r}-134 \mathrm{v}, 137 \mathrm{r}$ \\
\hline 28-04-1497 & Petrus Paulus Rossell & Guillermus de Podio & Joan Esteve & 3596 & $135 \mathrm{r}-135 \mathrm{v}, 136 \mathrm{r}$ \\
\hline 27-04-1498 & Petrus Paulus Rossell & Guillermus de Podio & Joan Esteve & 3596 & $132 \mathrm{r}-132 \mathrm{v}, 139 \mathrm{r}$ \\
\hline 29-04-1499 & Petrus Paulus Rossell & Guillermus de Podio & Jaume Esteve & 3605 & $10 \mathrm{r}-11 \mathrm{r}$ \\
\hline
\end{tabular}

Taula 1. Canonge rector de les escoles del cant i el seu substitut (1486-1499) ${ }^{56}$.

És evident que aquest Guillermus de Podio era el tractadista, una autoritat musical com era el mestre de les escoles del cant de la seu de València, qui en 1495 publicava en la mateixa ciutat on residia la seua obra Ars musicorum i qui dedicà l'Enchiridion al cabiscol de la catedral on exercia dit càrrec. També sembla clar que es tractava d'aquell "mossèn Podio, prevere mestre de cant" que apareixia juntament amb "mossèn Noffre, sonador del orgue de la Seu" com a experts visuradors en els esmentats capítols de 1489 per a la construcció de dos orgues a la parròquia de Sant Tomàs a València. No obstant això, tot i la presència provada a la seu de València de Guillem Molins de Podio, com a beneficiat, i de Guillermus de Podio, com a mestre de cant, res no ha demostrat fins ara que no foren dos sinó una mateixa persona.

El document que estableix la connexió definitiva és una provisió, del vicari general de la diòcesi valenciana, Guillem Ramon de Centelles, per la qual es decreta la col-lació de Gaspar Carles de Cabanyelles, canonge de València, en el "simplex perpetuum beneficium ecclesiasticum in ecclesia Valentina ad altare seu in capella sub beati Jacobi Apostoli invocacione et honorificencia per serenissimum dominum regem Jacobum recolende memorie, fundatum et institutum", que havia quedat vacant "per obitum venerabilis viri domini Guillermi de Podio, presbiteri, ultimi ac inmediati eiusdem possessoris" ${ }^{57}$. L'escrit, datat el primer de novembre de l'any 1500, no només ens informa que el tractadista era ja mort aquell dia, sinó que en el moment de l'òbit posseïa el benifet en la capella de Sant Jaume de la seu valentina que havia instituït el rei en Jaume, títol semblant al d'aquell que gaudia Guillem Molins de Podio el 1480, com ja s'ha vist. A més, sabem que aquest benifet, que havia estat en possessió del mestre de cant de la seu, tenia una renda assignada de vint-i-dues lliures anuals ${ }^{58}$.

La seu de València posseïa més de dos-cents benifets en l'època. Per tant, era habitual que en una mateixa capella catedralícia n'hi haguera diversos i amb la mateixa advocació. A més, els instituïdors, de vegades, en fundaven més d'un. Per tant, caldria plantejar-se la pregunta de si podria ser que els benifets de què gaudien Guillem Molins i Guillem de Podio no foren els mateixos malgrat haver sigut fundats per

56 La taula inclou les localitzacions a l'Arxiu de la catedral de València $(\boldsymbol{E}-V A c)$ dels capítols pasquals referits: data, notari capitular, número de volum i foliació.

57 Arxiu Diocesà de València, Manuale 1498-1500, sign. 337/001, 1 de novembre de 1500. Vegeu-ne un detall a la figura 5. Vegeu la transcripció i la traducció completes del document a l'apèndix documental, doc. 2.

58 "Ítem, per mort de mestre Podio, per lo benefici sots invocació de sent Jaume, de valor de vint e dos libres, posehix lo reverent mossèn Cabanyelles, canonge de València, a de pagar honze liures" [E-VAc, dobles i aniversaris, núm. 1075, rebudes de l'any 1500, s.f.]. 
la mateixa persona en la capella i l'advocació del mateix sant. La resposta ens la proporcionen els llibres de benifets de la seu. Segons aquestes fonts, en l'època hi havia vuit benifets en la capella de Sant Jaume, dels quals només un havia sigut instituït pel rei Jaume I, sota l'advocació del mateix sant, amb data d'institució de 5 de febrer de 1245. Era de patronat reial i l'únic dotat amb vint-i-dues lliures de renda anual $^{59}$. No hi ha, per tant, possibilitat que foren benifets diferents.

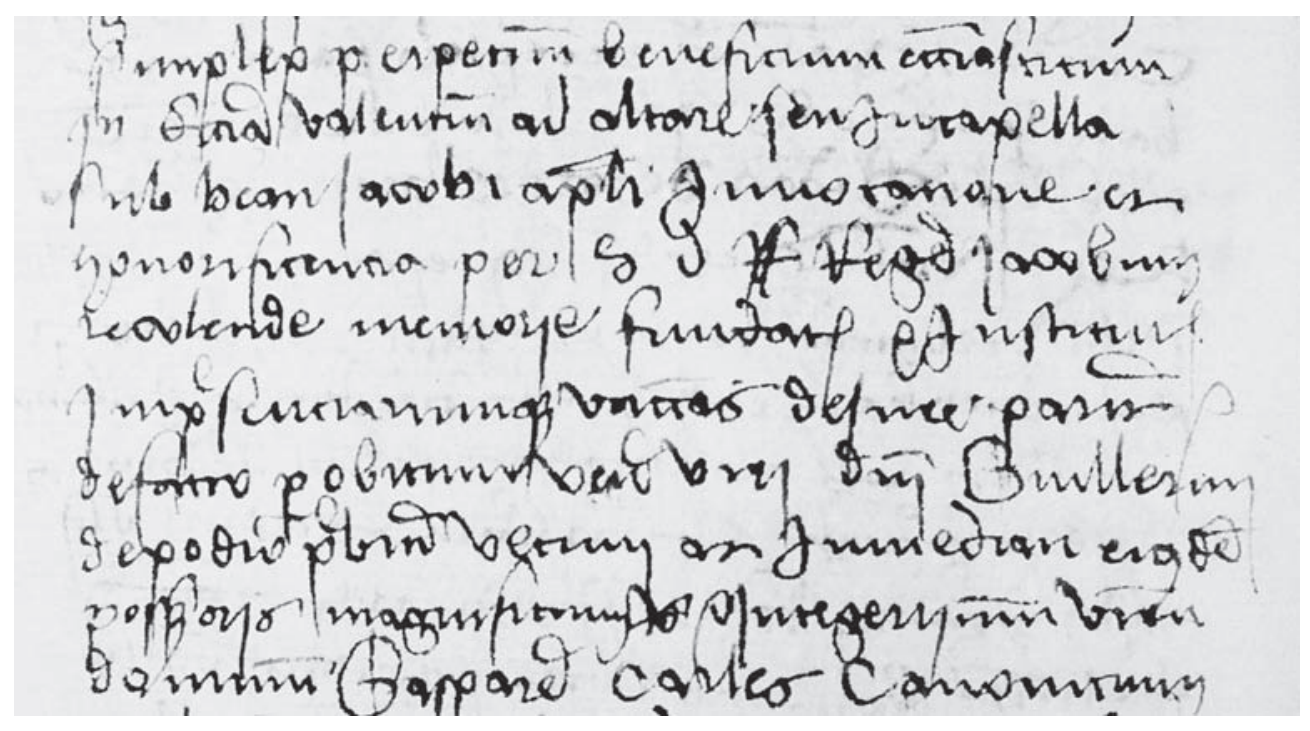

Figura 5. Detall de la provisió del vicari general de València [Arxiu Diocesà de València, sign. 337/001, 1 de novembre de 1500] ${ }^{60}$.

Com a conseqüència, resulta clar que Guillem Molins i Guillermus de Podio no eren dos sinó una mateixa persona que, com era molt habitual a l'època, utilitzava dos formes nominals diferents per a identificar-se -probablement un patronímic i un sobrenom- de manera indistinta, o fins i tot els dos alhora ${ }^{61}$. Per tant, s'ha pogut confirmar documentalment la hipòtesi subtilment apuntada per Higini Anglès i posteriorment defensada, malgrat que sense el suport general, per Josep Maria Gregori. Aquesta identificació provada, a més, explica perfectament l'esment a les pràctiques litúrgiques a Girona que fa el tractadista a l'Ars musicorum, on demostra coneixements específics adquirits durant la seua estada en aquesta ciutat com a membre capitular de la seu ${ }^{62}$.

$59 \boldsymbol{E}$-VAc, núm. 1554, fol. 81r; $\boldsymbol{E}$-VAc, núm. 1553, f. 101v.

60 Vegeu la transcripció i la traducció completa del document a l'apèndix documental, doc. 2.

61 Exemple d'ús simultani ("Guillermus Molins de Podio") és precisament el document ja esmentat que va fer sospitar a Anglès de la identificació.

62 “ $[. .$.$] similiter quicquid in missa ut enim in quibusdam ecclesiis et in Gerundensis inter ceteras comperimus sequentem$ trobum sive prefationem ante introitum misse prime dominice adventus eiusdem modi cum illo existentem decantant [...]" ([...] hem sabut que en algunes esglésies, i entre altres en les de Girona, canten el següent trop o prefaci abans de l'introit de la missa del 
Finalment, s'ha d'afegir que cal descartar definitivament la hipòtesi de J. Ruiz de Lihory, que identificava el músic Guillermus de Podio amb un cert Guillem Puig, beneficiat a Alzira. La documentació que s'ha pogut trobar en la recerca sobre aquest darrer personatge, posseïdor d'un benifet en l'altar de Sant Martí de l'església parroquial de Santa Caterina d'aquesta vila, demostra clarament i reiteradament que era només clergue simplement tonsurat encara l'any $1483^{63}$, dada totalment incompatible amb l'ordenació presbiteral del tractadista, constatada repetidament des de l'any 1446 en els documents fins ara coneguts ${ }^{64}$.

\section{CONCLUSIÓ}

El resultat de la revisió de la bibliografia existent referent a la biografia del tractadista Guillermus de Podio ens mostra un panorama al temps tan exigu com poc aclaridor. Les dades incontestables i d'acceptació general es redueixen a la seua condició de prevere i l'origen hispànic. La major part de la resta d'informació trobada és el resultat d'una sèrie d'hipòtesis sobre la seua identitat, nom i origen que, a causa de la manca d'una base documental, no han arribat a gaudir d'una acceptació plena, a més d'unes poques dades aillades, majoritàriament presentades sense justificació documental. Per tant, la pregunta retòrica de Stevenson que encapçala aquest treball continuava tenint actualitat al començament de la investigació.

Les noves aportacions documentals ací presentades condueixen definitivament a l'acceptació de la identificació entre Guillem Molins i Guillermus de Podio. D'aquesta manera, les dades fins ara conegudes sobre la trajectòria professional de Guillem Molins, juntament amb les ara presentades sobre el seu càrrec de mestre de cant a la seu de València, poden ser considerades sens dubte com a pertanyents al tractadista. Tota aquesta informació cobreix més de mig segle (1446-1500) de la seua dilatada vida professional, la qual ja havia arribat al final el 1500. Si, a més, es té en compte que el 1446 ja era ordenat de prevere, hem de pensar que el seu any de naixement podria estar prop de 1420, si no abans, la qual cosa ens mostra clarament que l'imprès de l'Ars musicorum va veure la llum quan l'ancià autor tenia al voltant de 75 anys d'edat, si no més, i que va escriure l'Enchiridion amb, almenys, una edat semblant. Aquesta circumstància no hauria d'oblidar-se a l'hora de realitzar valoracions sobre el conservadorisme de la seua obra, tradicionalment gens afavoridores, especialment quan ha sigut comparat amb el renovador Ramos de Pareja, qui pertanyia ja a una generació posterior.

primer diumenge d'Advent, de la mateixa manera juntament amb el que existeix [...]) [PoDIo, Guillermus de: Ars Musicorum, op. cit., fol. 36r]. La cursiva s'ha usat per a destacar el text i no apareix a l'original. L'existència d'aquesta referència a la seu gironina ja ha sigut observada a GüMPEL, Karl-Werner: "Guillermus de Podio...”, op. cit., col. 249.

63 Aquesta condició de clergue simplement tonsurat apareix explícitament en algunes actes notarials localitzades [ $\boldsymbol{E}$-VAcp, protocols notarials, not. Francesc Soler, núm. 2163, 16 de desembre de 1478; ibid., núm. 2166, 30 d'octubre de 1481; ibid., núm. 2166, 16 de setembre de 1483]. En els altres documents localitzats on apareix aquest personatge, és qualificat simplement com a "clergue" $[\boldsymbol{E}$-VAcp, protocols notarials, not. Francesc Soler, núm. 2164, 3 de febrer de 1479; ibid., núm. 2166,3 de novembre de 1481; ibid., núm. 2167, 23 de desembre de 1484; ibid., 18 de desembre de 1485; ibid., núm. 2176, 26 d'octubre de 1499] o fins i tot com a "estudiant" [E-VAcp, protocols notarials, not. Francesc Soler, núm. 2168, 10 d'octubre de 1487; ibid., núm. 2170 , fol. 41r-42r, 6 de maig de 1489; ibid., núm. 2172, 12 de novembre de 1492] però mai com a prevere.

64 La primera referència que la bibliografia ens dóna d'aquesta condició és: “Guillem Molins, Pbre... 1446, 1457...” [Mas, Josep: "Nota històrica...", op. cit.]. 
Mestre de cant a la catedral de Barcelona, cantor del rei Joan II d'Aragó i, finalment, mestre de cant a la seu de València, són els oficis musicals fins ara coneguts i contrastats que va exercir Guillem Molins àlies de Podio ${ }^{65}$, autor d'Ars musicorum i Enchiridion de principiis musice discipline. Sobre aquesta base, és ja possible construir amb detall la seua biografia.

\section{APÈNDIX DOCUMENTAL}

Localització. $\boldsymbol{E}$-VAcp, not. Bartomeu Lloscos, núm. 21204, 21 de març de 1480.

Assumpte. Guillem Molins, prevere beneficiat en la seu de València en el benifet instituït pel rei en Jaume sota l'advocació de sant Jaume, constitueix en procuradors seus Jofré Gostant, canonge, Daniel Genovés, prevere racioner en la seu de Saragossa, i Pedro Pifán, prevere beneficiat en l'església de Santa Engràcia de Saragossa, per fer en el seu nom diverses gestions de permuta amb un benifet en l'església de Santa Engràcia de Saragossa, sota l'advocació de santa Engràcia i sant Jeroni, i la vicaria perpètua de La Puebla de Alfindén, extramurs de Saragossa, sota l'advocació de santa Maria.

\section{Transcripció.}

Martis, XXI marcii anno predicto.

Venerabilis vir dominus Guillermus Molins, presbiter in ecclesia Valentina, beneficiatus de beneficio ibidem instituto sub honorificencia beati Jacobi Apostoli per serenissimum dominum nostrum, dominum Jacobum dive memorie, ac presbiter eciam de capitulo ecclesie Gerundensis, gratis, etc., constituit procuratores suos certos etc., et quo etc., ita tamen etc., venerabiles viros Janfridum Gostanti, canonicum, Danielem Genoves, presbiterum porcionarium ecclesie Cesaraugustane, et Petrum Pifan, presbiterum beneficiatum in ecclesia Sancte Engracie eiusdem civitatis, absentes etc., et [e]orum etc., ita quod non sit melior etc., videlicet ad acceptandum pro ipso domino constitutos, et eius nomine, cum cura et sine cura in quacunque diocesi fundata existant, cum illorum juribus, fructibus et redditibus universis; collationem, provisionem et investituram illorum petendum et habendum possessionemque realem, corporalem et actualem, apprehendendum, manutenendum et defendendum; canonicam obedienciam et manualem reverenciam et quodcunque juramentum de observandis statutis et consuetudinibus ecclesie vel ecclessiarum in qua seu quibus dicta benefficia fundata sint, faciendum et prestandum; et benefficium seu benefficia ipsa que nomine ipsius domini constituta ut premititur, acceptata fuerint, resignandum et renunciandum in manibus et posse reverendissimi domini archiepiscopi Cesaraugustani seu eius honorabilis domini vicarii generalis causa quidem permutationis fiende de eisdem cum vicaria perpetua loci de la Pobla, vulgo dicta de Ffinden, sub invocatione beate Marie extra menia civitatis Cesarauguste fundata, et cum beneficio seu

65 Utilitze la forma "de Podio" (i no Despuig ni Puig) perquè és l'emprada en les respectives llengües vernacles pels seus contemporanis a València (vegeu les notes 19 i 57) i pels tractadistes hispànics posteriors. 
capellania instituta in ecclesia Sancte Engracie civitatis predicte sub invocacione eiusdem Sancte Engracie et sancti Hieronimi per prefatum serenissimum dominum regem et non alias. Jurandum insuper quod in huiusmodi permutacione fienda non invenit etc.; collationem, provisionem et investituram dictorum benefficii et vicarie perpetue petendum et habendum, et possesionem illorum adipiscendum et manutenendum cum illorum juribus et pertinentiis universis; canonicam obedenciam et manualem reverentiam et quodcunque juramentum tam de servanda indempnitate jam dictorum beneficii et vicarie perpetue quam de observandis statutis et consuetudinibus ecclesie vel ecclesiarum in quibus, ut prefertur, constitutis et fundatis existunt, faciendum et prestandum; unum vel plures etc., procuratores etc., substituendi et eum vel eos etc., Et generaliter etc. Et que ego etc. Eciam si talia sint etc.

Testes inde sunt venerabiles Petrus Lopiç, presbiter in ecclesia Valentina beneficiatus, et Joannes de Prades, scriptor Valencie.

\section{Traducció.}

Dimarts, 21 de març de l'any predit.

El venerable senyor Guillem Molins, prevere en la seu de València, beneficiat del benefici instituït en aquesta pel sereníssim senyor nostre en Jaume, de divina memòria, sota l'honorificència de sant Jaume Apòstol, i a més prevere de capítol de la seu de Girona, de favor, etc., va constituir en procuradors seus vertaders etc., i on etc., de tal manera etc., els venerables en Jofré Gostant, canonge, Daniel Genovés, prevere porcioner de la seu de Saragossa, i Pedro Pifán, prevere beneficiat en l'església de Santa Engràcia de la mateixa ciutat, absents etc., i d'ells etc., de manera que no siga millor etc., és a dir constituïts per a acceptar per dit senyor, $i$ en el seu nom, [beneficis] amb cura i sense cura que existisquen fundats en qualsevol diòcesi, amb tots els seus drets, fruits i rendes; demanar i haver la seua col-lació, provisió i investidura i prendre, mantenir i defensar la possessió real, corporal i actual d'aquells; fer i prestar canònica obediència i manual reverència i qualsevol jurament sobre l'observació dels estatuts i costums de l'església o esglésies en la qual o en les quals estiguen fundats dits beneficis; i el benefici o beneficis que, constituïts en nom del mateix senyor, com s'ha dit abans, hagueren estats acceptats, resignar-los i renunciar-los en mans i poder del reverendíssim senyor arquebisbe de Saragossa o del seu honorable senyor vicari general, per causa de permuta i no per altra causa, que ha de ser feta dels mateixos amb la vicaria perpètua del lloc de la Pobla, vulgarment dita d'Alfindén, sota l'advocació de santa Maria, fundada extramurs de la ciutat de Saragossa, i amb el benefici o capellania instituït en l'església de Santa Engràcia de la ciutat predita sota l'advocació de la mateixa santa Engràcia i sant Jeroni pel dessusdit sereníssim senyor rei; jurar a més que en aquesta permuta que ha de ser feta, no es trobe etc.; demanar i haver la col-lació, provisió i investidura de dits benefici i vicaria perpètua; i obtenir i mantenir la seua possessió amb tots els drets i pertinències; fer i prestar canònica obediència i manual reverència; i qualsevol jurament, tant en la conservació de la indemnitat de dits benefici i vicaria perpètua, com en l'observació dels estatuts i costums de l'església o esglésies en les quals, com ja s'ha dit, existeixen constituïts i fundats; u o més etc., procuradors etc., de substituir a ell o ells etc., i en general etc., i que jo etc. A més, si siguen tals etc. 
Testimonis, doncs, són els venerables Pere Llopis, prevere beneficiat en la seu de València, i Joan de Prades, escrivà de València.

Localització. Arxiu Diocesà de València, Manuale 1498-1500, sign. 337/001, 1 de novembre de 1500.

Assumpte. Guillem Ramon de Centelles, vicari general de València, col-la a Gaspar Carles de Cabanyelles, canonge de València, el benifet instituït pel rei en Jaume en la capella de Sant Jaume de la seu de València, vacant per mort de Guillem de Podio, prevere, qui n'era el posseïdor anterior. Gaspar Cabanyelles és nomenat per Lluís de Cabanyelles, mestre-sala de Ferran II el Catòlic, per privilegi reial.

\section{Transcripció.}

Die intitulata prima mensis novembris anno a nativitate Domini $\mathrm{M}^{\mathrm{o}} \mathrm{D}^{\mathrm{o}}$, ante conspectum reverendi domini Guillermi Ramon de Centellis, vicarii generalis Valencie, constitutus personaliter magnificus Christoforus de Vasurto, miles, habitator civitatis Valencie, receptor pecuniarum baiulie generalis, qui loco, vice, et nomine $<$ ac in personam > nobilis Didaci de Torres, baiuli generalis regni Valencie, et de eius especiali et expressa sibi verbo tenus ut dixit, factus, exhibebat et producebat, exhibuit, produxit, insinuavit et notificavit eidem reverendo domino vicario generali quasdam serenissimi domini nostri domini, regis Fferdinandi, ffeliciter regnantis, litteras papireas patentes sigilloque secreto eius regie magestatis, a tergo illarum et $<$ more $>$ eius curie sigillat[a]s et munitas, sanas quidem et integras, non $<$ viciatas $>$, cancellatas, abolitas nec in aliqua earum parte suspectas, sed omni vicio et suspicione carentes ut prima earum fronte apparebat. In quarum dorso hec:

Al noble, magnífico, amado consejero e bayle general nuestro en el reyno de Valencia, don Diego de la Torre.

$\mathrm{Ab}$ intra vero reperta fuerunt verba que secuntur:

El Rey

Bayle General: en días passados feziemos gracia y mercé al magnífico amado maestrosala nuestro mossén Luys de Cabanyelles, de cincuenta llibras de renta pactadas en qualesquiere beneficios o rentas de la iglesia que fuessen de nuestro patronado en este reyno de Valencia por a la persona que ell nombrasse. E porque es nuestra voluntat que la dicha mercé haya efecto, por ende vos dezimos e encargamos y mandamos que, no obstante qualesquiere provisiones o cartas de Nos en contrario emanadas, ni lo que por Nos por una carta que de Burguos vos signemos os fue mandado que no proviéssedes ni hiziéssedes collar a ninguna persona beneficio alguno sino que por Nos fuesse nombrada, de los primeros beneficios que vaccaran en esse dicho reyno que serán de nuestro patronado, proveáys a la persona que por el dicho mossén Cabanyillas será nombrada asta en suma de las dichas cinquenta llibras, faziendo al vicario general que, en vaccando los dichos beneficios, colle aquellos a la dicha persona nombrada por el dicho nuestro maestrosala, car Nos dende agora por entonçe[s] aprovamos aquella y prestamos a ello nuestro consentimiento. E no fagáys el contrario por quanto es nuestra determinada voluntat. Data en la villa de Alcalá de Henares a XXX días del mes de deziembre, anyo mil cCCLXXXXVIII.

Yo, el Rey. 
L. Gonzales, secretario.

In Diversorum sigilli secreti, $V I^{\circ}$, folio XXXXVIII.

Ea propter dixit quod non solum predictarum litterarum <et mandati $>$ de super insertarum < vigore $>$ verum eciam verum eciam comissionis et facultatis sibi per dictum baiulum generalem sibi ut premittitur, datarum et concessarum presentabat, ac realiter et de facto presentavit ipsi reverendo domino vicario generali, seu coram eo, ad obtinendum simplex perpetuum beneficium ecclesiasticum in ecclesia Valentina ad altare seu in capella sub beati Jacobi Apostoli invocacione et honorificencia per serenissimum dominum regem Jacobum recolende memorie, fundatum et institutum, impresenciarumque vaccans de jure pariter et de facto per obitum venerabilis viri domini Guillermi de Podio, presbiteri, ultimi ac inmediati eiusdem possessoris, magnificum, et integerrimum virum, dominum Gasparem Carles ${ }^{66}$, canonicum Valentinum, per dictum magnificu $<\mathrm{m}>$ Ludovicum de Cabanyelles ad id nominatum, licet absentem, in personam tamen Gaspar Paschual, eius procuratoris, et pro eo suplicans etc. Et dictus reverendus dominus vicarius generalis admissa huiusmodi presentatione, collavit predictum beneficium dicto Gaspari Cabanyelles, et pro eo Gaspari Paschual, eius procuratore, presentis. Testibus Ludovico Borraç, presbitero in sede beneficiato, et Philipo de Abella, notario.

\section{Traducció.}

En el dia primer del mes de novembre de l'any de la nativitat del Senyor de 1500, constituït personalment davant la presència del reverend senyor Guillem Ramon de Centelles, vicari general de València, el magnífic Cristóbal de Vasurto, cavaller, habitant de la ciutat de València, receptor de les pecúnies de la batlia general, el qual, de fet en lloc, en vegada i nom <i en persona > del noble Diego de Torres, batle general del regne de València, conforme digué que li havia fet de viva veu especialment i expressament, exhibia i presentava, exhibí, presentà, insinuà i notificà al mateix reverend senyor vicari general una carta patent de paper del sereníssim senyor nostre el rei en Ferran, feliçment regnant, amb el segell secret de sa reial majestat al dors de la mateixa i segellada i protegida <a la manera $>$ de sa cúria, certament sana $i$ íntegra, no <viciada>, cancel·lada, abolida ni sospitosa en part alguna, sinó mancada de tot vici i sospita, com apareixia a primera vista. En el dors de la carta [es lligen] les següents coses:

[vegeu el text castellà en la transcripció]

A la part de dins, foren trobades les paraules que segueixen:

[vegeu el text castellà en la transcripció]

En "Diversos del segell secret", vi, foli xxxxvIII.

Per aquesta raó, digué que no només <amb la força> de la predita carta <i mandat> inserida més amunt, sinó també per la comissió i facultat donades i concedides a ell per dit batle general, com s'ha dit abans, presentava i realment i de fet va presentar -al mateix reverend senyor vicari general, o davant d'ell,

66 En realitat hauria de dir: "Gaspari Carles Cabanyelles", el qual és qui en definitiva rep el benefici [vegeu nota 57]. Aquest personatge havia sigut rebut com a canonge el 20 de febrer de 1484 [E-VAc, not. Jaume Esteve, núm. 3596, any 1486, fol. 2r]. 
per obtenir el benifet eclesiàstic perpetu simple en la seu de València en l'altar o capella sota l'advocació i honorificència de sant Jaume, fundat i instituït pel sereníssim senyor rei Jaume, de venerada memòria, i en el moment actual vacant de dret i de fet per mort del venerable senyor Guillem de Podio, prevere, últim i immediat possessor del benefici- el magnífic i integríssim senyor Gaspar Carles, canonge de València, nomenat per aquest benefici pel dit magnífic Lluís de Cabanyelles -malgrat que absent, no obstant això representat en la persona de Gaspar Paschual, el seu procurador, i suplicant per ell etc.-. I dit reverend senyor vicari general, admesa aquesta presentació, va col-lar el predit benefici a dit Gaspar Cabanyelles, i per ell Gaspar Paschual, el seu procurador, present. Van ser testimonis Lluís Borraç, prevere beneficiat en la seu, i Felip de Abella, notari.

Recibido: 06/04/2010

Aceptado: 27/04/2010 